WellBeing International

WBI Studies Repository

1988

\title{
Eavesdropping by Bats: The Influence of Echolocation Call Design and Foraging Strategy
}

Jonathan Balcombe

M. Brock Fenton

Follow this and additional works at: https://www.wellbeingintlstudiesrepository.org/acwp_asie

Part of the Animal Structures Commons, Animal Studies Commons, and the Other Animal Sciences Commons

\section{Recommended Citation}

Balcombe, J.P., \& Fenton, M.B. (1988). Eavesdropping by bats: The influence of echolocation call design and foraging strategy. Ethology, 79, 158-166.

This material is brought to you for free and open access by WellBeing International. It has been accepted for inclusion by an authorized administrator of the WBI Studies Repository. For more information, please contact wbisr-info@wellbeingintl.org.

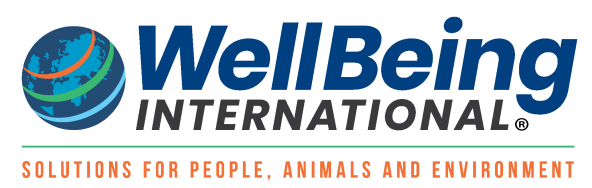




\title{
Eavesdropping by Bats: \\ The Influence of Echolocation Call Design \\ and Foraging Strategy
}

\author{
Jonathan P. Balcombe \& M. Brock Fenton
}

\begin{abstract}
Recommended Citation:
Balcombe, J.P., \& Fenton, M.B. (1988). Eavesdropping by bats: The influence of echolocation call design and foraging strategy. Ethology, 79, 158-166.
\end{abstract}

\begin{abstract}
We used playback presentations to free-flying bats of 3 species to assess the influence of echolocation call design and foraging strategy on the role of echolocation calls in communication. Near feeding sites over water, Myotis lucifugus and M. yumanensis responded positively only to echolocation calls of conspecifics. Near roosts, these bats did not respond before young of the year became volant, and after this responded to presentations of echolocation calls of similar and dissimilar design. At feeding sites Lasiurus borealis responded only to echolocation calls of conspecifics and particularly to "feeding buzzes". While Myotis, particularly subadults, appear to use the echolocation calls of conspecifics to locate feeding sites, L. borealis appears to use the calls of a foraging neighbor attacking prey to identify opportunities for 'stealing' food.
\end{abstract}

\section{NTRODUCTI ON}

Echolocation may be the most common mode of prey detection in the Microchiroptera (BUSNEL \& FISH 1980); it is an active process that provides bats with an acoustic image of their surroundings. Unlike passive mode of orientation, echolocation can make an animal conspicuous to prey (FULLARD 1987) and to conspecifics. The gregarious Myotis lucifugus responded positively to playback presentations of conspecific echolocation calls while en route to feeding sites, and at roosting and hibernation sites (BARCLAY 1982), while foraging Euderma ma_culatum responded adversely to playback presentations of conspecific echolocation calls (LEONARD \& FENTON 1984). These two studies provide experimental evidence that eavesdropping behaviour occurs in the Microchiroptera, and that behavioural responses differ between species.

The purpose of this study was to determine how foraging habits and echolocation-call characteristics ("call design") influence the eavesdropping response. We tested the hypothesis that bats are responsive to echolocation calls most similar in design to their own. 
This hypothesis depends on the assumption that a bat's echolocation-call characteristics (duration, frequency bandwidth, temporal pattern of frequency change over time, and intensity) reflect its foraging strategy (FENTON 1986; ALDRIDGE \& RAUTE BACH 1987). To test it, we presented a range of echolocation calls to free flying Myotis lucifugus, Myotis yumanensis and Lasiurus borealis (Vespertilionidae) at feeding and roosting sites in southern British Columbia and southern Ontario, Canada. The Myotis use short, broadband echolocation calls, the L. borealis long, narrowband ones. In these bats feeding buzzes (high pulse repetition rates) identify individuals attacking prey items.

\section{MATERI AL AND METHODS}

Field work was conducted in the Okanagan Valley, British Columbia from May to the end of July, 1985, and at Pinery Provincial Park, Ontario in August, 1985 and from May to the end of July, 1986. In British Columbia, playback presentations were performed along the Okanagan River and at the edge of a 5-ha lake where swarms of bats, mainly $M$. yumanensis and $M$. lucifugus foraged. Other presentations were performed outside an abandoned warehouse that housed a colony of over $600 \mathrm{M}$. yumanensis. In Ontario, we presented playbacks outside a building colony of $150 \mathrm{M}$. lucifugus in a building in Grand Bend, $1 \mathrm{~km}$ north of the Pinery Provincial Park boundary. Inside the park, playbacks were conducted at five floodlight locations where Lasiurus borealis and Lasiurus cinereus foraged.

Table 1 describes characteristics of the stimuli presented in this study. The recorded stimuli were made using a Racal Store 4D tape recorder operated at $76 \mathrm{~cm} / \mathrm{s}$, and a broadband ultrasonic microphone (SIMMONS et al. 1979). Four of the stimuli were presented to all bats at all locations in the study. These "principal stimuli" were foraging calls representing short, broadband signals (Myotis spp., Eptesicus fuscus ) and long, narrowband ones (Lasiurus cinereus and Rhinolophus megaphyllus). The Myotis stimulus was of a feeding swarm of about $50 \mathrm{M}$. yumanensis and $\mathrm{M}$. lucifugus recorded over the Okanagan River. The E.fuscus were recorded near Millbrook, New York; the L. cinereus were recorded at Pinery Provincial Park and by R. M. R. Barclay at the University of Manitoba Field Station, Delta, Manitoba and the R. megaphyllus near Chillagoe, Australia (FENTON 1982). We also presented several other stimuli during the study (Table 1): to $\mathrm{M}$. lucifugus at the Ontario roost we presented reversed Myotis echolocation calls, artificially produced conspecific calls (described by BARCLAY 1981), and "white noise" from a General Radio Company Type 1390-B Random Noise Generator; tO foraging L. borealis we presented conspecific echolocation calls (recorded at Pinery Provincial park), reversed conspecific calls, repeated conspecific feeding buzzes (produced by selectively editing buzzes from a recording of foraging L. borealis), and white noise.

Playback stimuli were presented from a Racal Store 4D tape recorder operated at $76 \mathrm{~cm} / \mathrm{s}$, amplified (SIMMONS et al. 1979) and broadcast through an $8.5 \mathrm{~cm}$ diameter mylar electrostatic speaker (VON MACHMERTH et al. 1975) erected $3 \mathrm{~m}$ above ground level or held in the hand. Outgoing signals were monitored on a Telequipment D32 oscilloscope, and surrounding bat activity was continuously monitored using a QMC Mini Bat Detector (QMC Instruments, 229 Mile End Road, London) tuned to $40 \mathrm{kHz}$ and placed $1 \mathrm{~m}$ beneath the speaker. Each signal was recorded at $1 \mathrm{~V}$ peak-to-peak on the oscilloscope, then boosted to $20 \mathrm{~V}$ peak-to-peak by the power amplifier for playback. For most presentations, free flying 
bats could be seen by back-lighting them against the night sky, but as needed, we used a Zoomar night vision scope with a Cosmicar 25- $\mathrm{mm}$ television lens. Each playback trial consisted of 2 min of silence and 2 min of stimulus, the order of which was assigned at random. The different stimulus types (typically four) being presented on a given night comprised a block, and a block of trials typically consisted of four randomly ordered stimuli. To minimize the potential effects of varying levels of bat activity during the night, a complete block was presented before another was started. We started a playback presentation when there was at least one bat flying within range of the QMC mini bat detector (ca. 20m). Bats which flew within $2 \mathrm{~m}$ of the speaker were counted, and the observer used two hand counters to score bat passes during the two halves of a trial. For all playback trials, the observer was unaware of the stimulus type being presented, or whether the trial was initiated by a stimulus or a silent period. Sometimes individual bats made several passes at the speaker during a trial (see Results). Thus, while counts corresponded to the number of bat passes at the speaker, they did not always represent the number of individual bats which flew past the speaker.

Table 1: Characteristics of sounds used in playback presentations. Durations: durations of individual sounds in stimulus presentations; FM: frequency modulated, CF: constant frequency; bandwidth: highest and lowest frequencies in the stimuli; no. of feeding buzzes: number presented during one 2-min period; asterisks: principal stimuli

\begin{tabular}{|l|c|c|c|c|}
\hline Stimulus sound & $\begin{array}{c}\text { Duration } \\
\text { in ms }\end{array}$ & Design & $\begin{array}{c}\text { Bandwidth } \\
\text { in kHz }\end{array}$ & $\begin{array}{c}\text { No. of } \\
\text { feeding } \\
\text { buzzes }\end{array}$ \\
\hline Myotis spp.* & 3 & steep FM & $100-40$ & 12 \\
\hline Eptesicus fuscus* & 5 & steep FM & $45-30$ & 8 \\
\hline Lasiurus borealis & 10 & shallow FM & $50-30$ & 8 \\
\hline L. cinereus* & 15 & shallow FM & $30-20$ & 2 \\
\hline Rhinolophus megaphyllus* & 20 & CF- FM & $70-62$ & 0 \\
\hline L. borealis buzz & 3 & steep FM & $60-40$ & 51 \\
\hline Artificial Myotis & 3 & steep FM & $80-40$ & 0 \\
\hline White noise & continuous & unstructured & $5-160$ & 0 \\
\hline
\end{tabular}

To help to interpret the results of the playback experiments, we also made other observations of the bats we studied, noting the number of bats visible or audible in the playback area, their foraging behaviour, interactions between bats, and their orientation to the speaker.

To determine the responsiveness of bats to a given stimulus, we compared bat passes during the stimulus and silent presentation periods. Because the data' were non-normally distributed and contained high variance, they were analyzed non-parametrically. We computed difference scores by subtracting the silent period count from the stimulus period count of each individual playback presentation, then used the Wilcoxon matched-pairs signed-ranks test (SIEGEL 1956) to compare the number of trials for which the difference scores were positive $(+)$ with the number of trials for which the difference scores were negative (-). Significance levels for all statistics are defined by $p<0.05$. Since Myotis respond positively to meaningful stimuli (BARCLAY 1982), we used one-tailed tests to 
analyze our data from presentations to Myotis. However, since we did not know how L. borealis might react, we analyzed those data with two-tailed tests.

\section{RESULTS}

\section{Playback Experiments}

During playback trials, responsive bats were easily recognized. A Myotis interested in the speaker flew towards it from the front and swerved inwards after passing it, or circled the speaker one or more times. An unresponsive bat flew straight past the speaker from any direction. Responsive L. borealis swooped down at the speaker and occasionally circled it one or more times.

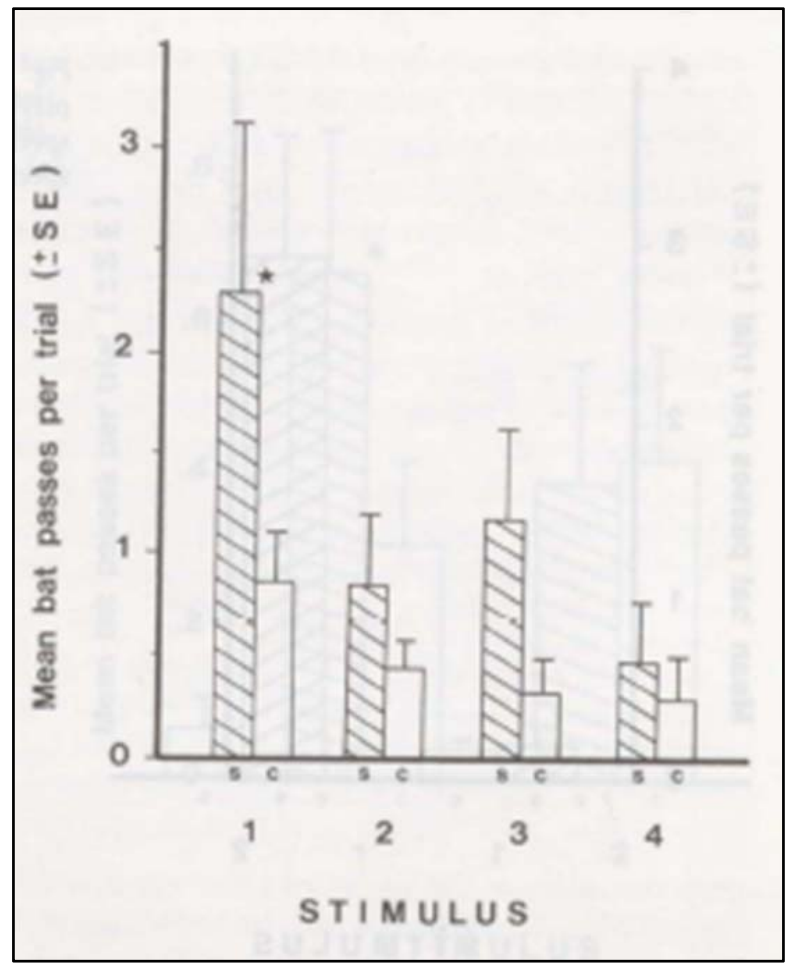

Fig. 1: Responses of foraging Myotis lucifugus and Myotis yumanensis to presentations of the principal stimuli in British Columbia in 1985. The playback presentations included recordings of the echolocation calls of: 1$)$ Myotis $(N=33), 2)$ Eptesicus fuscus $(N=27), 3)$ Lasiurus cinereus $(N=18), 4)$ Rhinolophus megaphyllus $(N=15)$. $\mathrm{s}$ : stimulus periods, c: control (silent) periods, asterisk: significant differences 


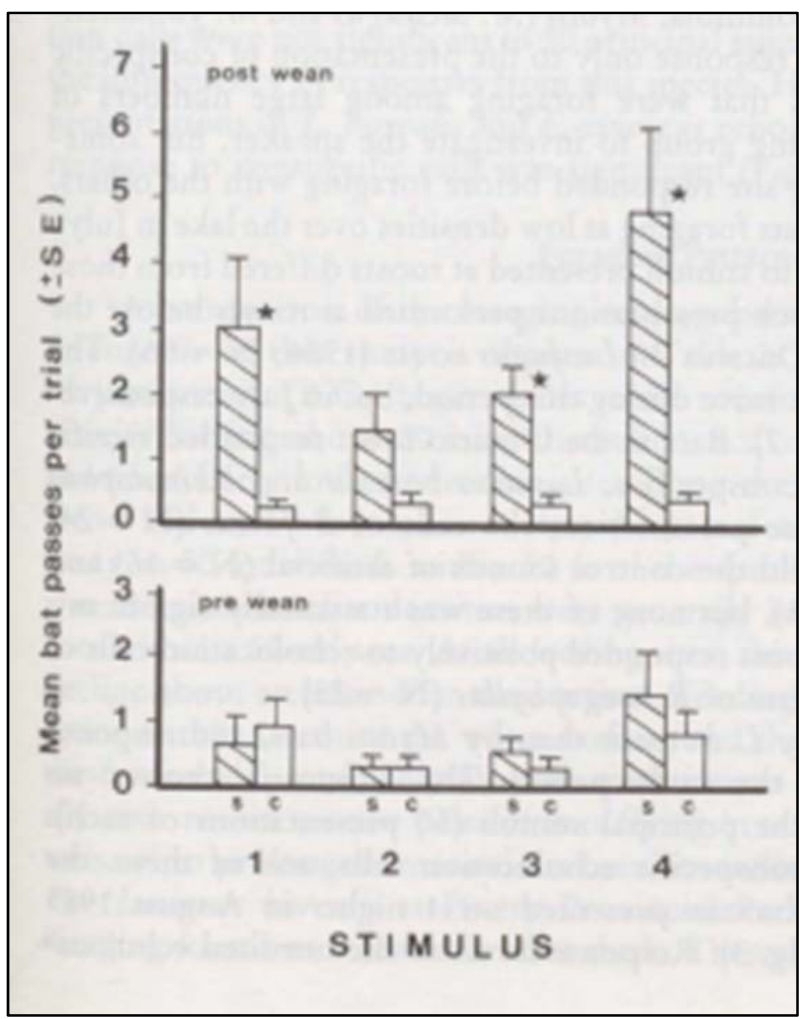

Fig. 2: Responses of Myotis lucifugus at the Ontario roost site (1986) to the principal playback presentations of recorded echolocation calls including 1) Myotis, 2) Eptesicus fuscus, 3) Lasiurus borealis, 4) Rhinolophus megaphyllus. A total of 14 presentations of each stimulus was made before weaning, and 24 of each after weaning. Explan. See Fig. 1 


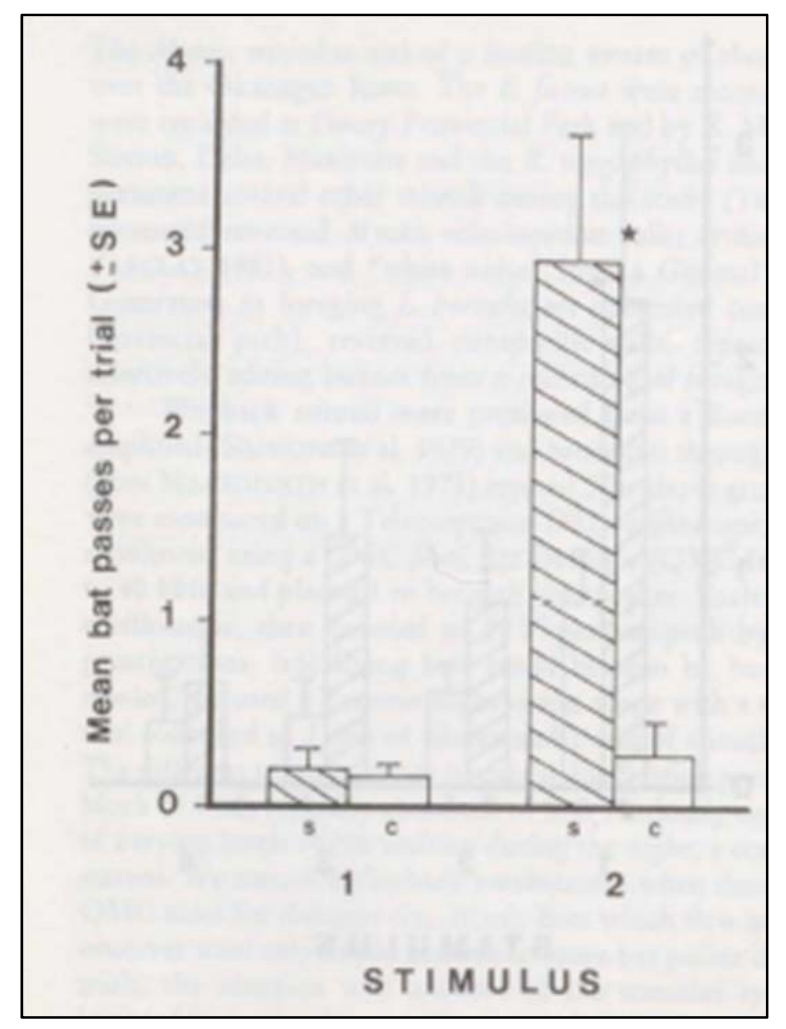

Fig. 3: Responses of Laszurus borealis to playback presentations of unedited conspecific calls (stimulus $1, \mathrm{~N}=25$ ) and conspecific feeding buzzes (stimulus 2, $\mathrm{N}=25$ ) in 1985. Explan. see Fig. 1

At feeding sites in British Columbia, Myotis ( $M$. lucifugus and M. yumanensis) showed a significant positive response only to the presentation of conspecific echolocation calls (Fig. 1 ). Bats that were foraging among large numbers of conspecifics never left the foraging group to investigate the speaker, but sometimes bats arriving at the feeding site responded before foraging with the others. We also observed responses by bats foraging at low densities over the lake in July.

Myotis patterns of response to stimuli presented at roosts differed from those at feeding sites. The only playback presentations performed at roosts before the end of June were those at the Ontario $\mathrm{M}$. lucifugus roost (1986; $\mathrm{N}=96$ ). The bats were almost entirely unresponsive during this period, but in July responsiveness increased dramatically (Fig. 2). Bats at the Ontario roost responded significantly to echolocation calls of conspecifics, Lasiurus borealis and Rhinolophus megaphyllus (Fig. 2). During one presentation, the calls of E. fuscus ( $\mathrm{N}=24$ ) elicited a positive response, as did the control sounds of artificial ( $\mathrm{N}=$ 16) and reverse conspecific calls $(N=16)$, but none of these was statistically significant. Myotis yumanensis at the B.C. roost responded positively to echolocation calls of conspecifics $(N=40)$ and to those of $R$. megaphyllus $(N=25)$.

We saw fewer responses by L. borealis than by Myotis bats, and response levels did not fluctuate across the study period. The L. borealis showed no significant response to any of the principal stimuli (50 presentations of each). L. borealis responded only to conspecific 
echolocation calls, and of these, the recording of repeated feeding buzzes presented on 4 nights in August 1985 elicited the greatest response (Fig. 3). Response levels to the unedited echolocation calls were not significant in 50 principal stimulus trials during 1986, reflecting the infrequency of responses from this species. However, in a separate series of 72 presentations of L. borealis and L. cinereus echolocation calls on 4 nights in 1986, response to conspecific calls was significant (Fig. 4 ).

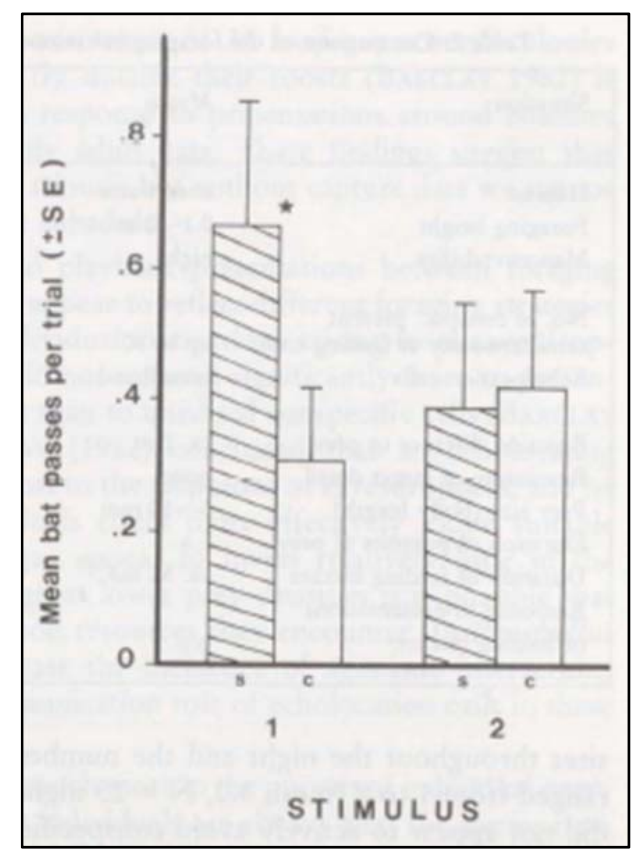

Fig. 4: Responses of Lasiurus borealis to playback presentations of echolocation calls of conspecifics (stimulus 1, $\mathrm{N}=36$ ) and of Lasiurus cinereus (stimulus 2, $\mathrm{N}=36$ ) in 1986. Explan. see Fig. 1

\section{Foraging Patterns}

A comparison of the foraging ecology between the two Myotis species and L. borealis in this study is shown in Table 2. Myotis lucifugus (Ontario) and M. yumanensis (B.C.) began to leave the roost at dusk producing a peak in bat activity lasting about $20 \mathrm{~min}$; thereafter, activity near the roost subsided and remained fairly low. At feeding sites along the Okanagan River, bats began to arrive and feed a few minutes after dusk, and within 10-20 min, there were as many as 50 individuals within $50 \mathrm{~m}$ of the speaker. At the Lake site, the pattern was the same but bat densities were generally lower, sometimes with only three bats within a 50-m2 area. At all feeding sites, the number of bats usually began to decline about an hour after their arrival. Feeding Myotis spent most of their time flying within 10 em of the water surface, and their flight patterns were erratic as they swerved, presumably to catch small insects and avoid other bats. Occasionally near roosts we saw pairs of bats flying in tandem; at feeding sites, however, we saw no prolonged interactions between individuals.

Lasiurus borealis at Pinery Provincial Park in Ontario arrived at floodlit foraging locations a few min after dusk. These bats remained active at foraging sites throughout the night and 
the number of individuals present at the lights ranged from 1 to 8 (mean $3.0, N=25$ nights). Within a floodlit area, L. borealis did not appear to actively avoid conspecifics. And while individuals usually did not forage in close proximity to others, at times up to four bats hunted around the same light. These bats typically flew 5 to $10 \mathrm{~m}$ above the ground making rapid dives to within $20 \mathrm{~cm}$ of the ground. Observations of pursued insects and culled insect parts indicated that these bats fed almost exclusively on medium-sized moths (10-30 mm body length). Individuals expended considerable effort in chasing each moth and sometimes ( $30 \%$ of $15^{\prime} 5$ ) pursuits lasted over $5 \mathrm{~s}$. During pursuits bats emitted feeding buzzes while in erratic, twisting, stalling flight. On 13 occasions in 1986 we saw a second L. borealis join in the chase as if trying to intercept the pursued insect. In addition to these prey-associated bat interactions, we saw 92 aerial chases during the study. Chases involved two L. borealis flying rapidly one in front of the other and lasted between 2 and $20 \mathrm{~s}$ (typically 3-5 s). The two bats invariably flew within $50 \mathrm{~cm}$ of one another, and sometimes (9\%) appeared to make physical contact.

Table 2: Comparison of the foraging behavior of Myotis spp. and Lasiurus borealis

\begin{tabular}{|c|c|c|c|}
\hline Situation & Myotis & $\begin{array}{l}\text { Lasiurus } \\
\text { borealis }\end{array}$ & Source \\
\hline Habitat & over water & open clearings & this study \\
\hline Foraging height & $0.1-2 \mathrm{~m}$ & $5-10 \mathrm{~m}$ & this study \\
\hline Manreuvrability & High & low & $\begin{array}{l}\text { ALDRIDGE } 1986 \\
\text { ALDRIDGE pers. } \\
\text { comm. }\end{array}$ \\
\hline $\begin{array}{c}\text { No. of conspec. Present } \\
\text { simultaneously at feeding sites }\end{array}$ & up to 50 & $0-4$ & this study \\
\hline Echolocation calls & Broadband & narrowband & $\begin{array}{c}\text { HERD \& FENTON } \\
\text { 1983; } \\
\text { BARCLAY } 1984\end{array}$ \\
\hline Reaction distance to prey & ca. $1 \mathrm{~m}$. & $5-10 \mathrm{~m}$ & this study \\
\hline Resolution of target detail & good & poor & $\begin{array}{c}\text { SIMMONS \& STEIN } \\
1980\end{array}$ \\
\hline Prey size (body length) & $3-10 \mathrm{~mm}$ & $10-30 \mathrm{~mm}$ & $\begin{array}{c}\text { ANTHONY \& KUNZ } \\
1977\end{array}$ \\
\hline Duration of pursuits of prey & $1 \mathrm{~s}$ & $1-5 \mathrm{~s}$ & this study \\
\hline Duration of feeding buzzes & ca. $50 \mathrm{~ms}$ & up to $1000 \mathrm{~ms}$ & this study \\
\hline $\begin{array}{l}\text { Response to presentation s of } \\
\text { feeding buzzes }\end{array}$ & n.s. & significant & $\begin{array}{l}\text { BARCLAY (1982), } \\
\text { this study }\end{array}$ \\
\hline
\end{tabular}

\section{SCUSSION}

Our results generally agree with others concerning eavesdropping on echolocation calls by microchiropteran bats (BARCLAy 1982; LEONARD \& FENTON 1984). Furthermore, our data on foraging My otis spp. and L. borealis support the hypothesis that bats are most responsive to echolocation calls most similar in design to their own, responding most often to the calls of conspecifics. The data for Myotis spp. near roosts do not support the hypothesis, as bats responded to calls of dramatically different design. 
The significant increase in responsiveness of $M$. lucifugus around colonies when young of the year began to fly outside their roosts (BARCLAY 1982) is repeated in our data. We found no response to presentations around colonies when the population comprised only adult bats. These findings suggest that subadults are responsive to auditory stimuli, but without capture data we cannot be certain that responding bats were subadults.

The differences in responses to playback presentations between foraging Myotis species and Lasiurus borealis appear to reflect different foraging strategies paralleled by differences in inter-individual interactions arising from eavesdropping (Table 2). While M. lucifugus did not respond significantly more to presentations of conspecific feeding buzzes than to unedited conspecific calls (BARCLAY 1982), the L. borealis did. BARCLAY (1982) concluded that an echo locating $M$. lucifugus suffered little (if any) cost to the responses of eavesdroppers, and he showed how eavesdropping individuals could more effectively locate suitable feeding areas. Individual $M$. lucifugus appear to invest relatively little in the pursuit of single prey items, although at lower prey densities it is possible that M. lucifugus take steps to protect food resources they encounter. In Pipistrellus pipistrellus low prey densities increase the incidence of agonistic interactions (RACEY \& Swwr 1985), but the communication role of echolocation calls in these interactions has not been explored.

Lasiurus borealis seem to invest much more in the pursuit of individual prey, and the bat's behaviour suggests that individuals are always alert for appropriate targets. The playback experiments with feeding buzzes demonstrate that part of being alert is cuing on the feeding buzzes of conspecifics. GRIFFIN (1958) suggested that foraging L. borealis exploited the feeding buzzes of conspecifics to identify the presence of a prey item. He reported that when one bat began to produce a feeding buzz while pursuing an insect, another conspecific often appeared and joined the chase. Our playback presentations of feeding buzzes support Griffin's interpretation of his observations.

Our data and those of GRIFFIN (1958) lead us to propose that L. borealis eavesdrop on conspecifics and use feeding buzzes to identify the presence of vulnerable prey. Two pieces of evidence support this proposal: 1) the strong positive response of these bats to playback presentations of conspecific feeding buzzes and 2) the interactions we observed between individuals pursuing prey. The long duration of prey pursuits can permit an individual to exploit the information conveyed by another's foraging calls.

It is tempting to refer to this behaviour as "piracy" (the stealing of food from another individual) as known from several species of birds (e.g., KALLA DER 1977; BURGER \& GOCHFELD 1981), from lizards (AUFFENBERG 1984) and from other mammals (KRUUK 1972), including bats (FENTON et al. 1983). The situation in L. borealis, however, differs from these examples of piracy because the prey had not yet been captured.

Our results increase the data base that relates a bat's foraging behaviour with the design of its echolocation calls. Furthermore, they indicate fundamental differences in inter-individual interactions during foraging activity. 


\section{ACKNOWLEDGMENTS}

We are grateful to M. LOCHER and D. BEARE for assistance in the field and to H. D. J. N. ALDRIDGE, D. AUDET, R. M. R. BARCLAY, R. M. BRIGHAM, J. CEBEK, H. G. MERRIAM, B.]. R. PHILOGE E, R. A. SUTHERS and V. WAI-PING for their comments on the manuscript. This research was supported by Natural Sciences and Engineering Research Council of Canada operating and equipment grants to MBF.

\section{LITERATURE CITED}

ALDRIDGE, H. D. ]. N., 1986: Manceuvrability and ecological segregation in the little brown bat (Myotis lucifugus) and yuma bats (Myotis yumanensis). Can.]. Zool. 64, 1878-1882.

--, \& I. L. RAUTENBACH, 1987: Morphology, echolocation and resource partitioning in insectivorous bats. J. Anim. Ecol. 56, 763-778.

ANTHO Y, E. L. P., \& T. H. Ku z, 1977: Feeding strategies of the little brown bat, Myotis lucifugus, in southern New England. Ecology 58, 775-786.

AUFFENBERG, W., 1984: Notes on feeding behaviour of Varanus bengalensis (Sauria: Varanidae). J. Bombay Nat. Hist. Soc. 80, 286--302.

BARCLAY, R. M. R., 1981: Interindividual use of echolocation calls: eavesdropping by the little brown bat, Myotis lucifugus. Ph. D. Thesis, Carleton Univ., Ottawa.

- -, 1982: Interindividual use of echolocation calls: eavesdropping by bats. Behav. Ecol. Sociobiol. 10, 271-275.

- -, 1984: Observations on the migration, ecology and behaviour of bats at Delta Marsh, Manitoba. Can. Field-Nat. 98, 331-336.

BURGER, J., \& M. GOCHFELD, 1981: Age-related differences in piracy behaviour of four species of Larus gulls. Behaviour 77, 242-267.

BUNNEL, R.G., \& J. F. FISH, eds., 1980: Animal Sonar Systems. ATO Adv. Study Inst. A28, Plenum Press, New York.

FENTON, M. B., 1982: Echolocation calls and patterns of hunting and habitat use of bats (Microchiroptera) from Chillagoe, North Queensland, Australia. Aust. J. Zoo I. 30, 417-425.

--, 1986: Design of bat echolocation calls: implications for foraging ecology and communication. Mammalia 50, 193-203.

--, C. L. GAUDET, \& M. L. LEONARD, 1983: Feeding behaviour of the bats Nycteris grandis and Nycteris thebaica (Nycteridae) in captivity. J. Zool. Lond. 200, 347-354.

FULLARD, J. H., 1987: Sensory ecology and neuroethology of moths and bats: interactions in a global perspective. In: Recent Advances in the Study of Bats. (FENTON, M. B., P. A. RACEY, \& J. M. V. RAYNER, eds.) Cambridge Univ. Press, Cambridge, pp. 244-272.

GRIFFIN, D. R., 1958: Listening in the Dark. Yale Univ. Press, New Haven. 
HERD, R. M., \& M. B. FENTON, 1983: An electrophoretic, morphological and ecological investigation of a putative hybrid zone between Myotis lucifugus and Myotis yumanensis (Chiroptera: Vespertilionidae). Can. ]. Zool. 61, 2029-2050.

KALLANDER, H., 1977: Piracy by black-headed gulls on lapwings. Bird Study 24, 186-- 194.

KRUUK, H., 1972: The Spotted Hyena. U niv. of Chicago Press, Chicago.

LEONARD, M. L., \& M. B. FENTON, 1984: Echolocation calls of Euderma maculatum (Chiroptera: Vespertilionidae): use in orientation and communication.]. Mamm. 65, 122125.

MACHMERTH, H. VON, D. THEISS, \& H.-U. SCHNITZLER, 1975: Konstruktion cines Luftultraschallgebers mit konstantem Frequenzgang im Bereich von $15 \mathrm{kHz}$ bis $140 \mathrm{kHz}$. Acustica 34, 81-85.

RACEY, P. A., \& S. M. Swift, 1985: Feeding ecology of Pipistrellus pipistrellus (Chiroptera: Vespertilionidae) during pregnancy and lactation. I. foraging behaviour. J. Anim. Ecol. 54, 205-215.

SIEGEL, S., 1956: Nonparametric Statistics for the Behavioral Sciences. McGraw-Hill, Toronto.

SIMMONS, J. A., \& R. A. STEIN, 1980: Acoustic imaging in bat sonar: echolocation signals and the evolution of echolocation. J. Comp. Physiol. 135, 61-84.

-- , M. B. FENTON, W. R. FERGUSO, M. JUTTI G, \& J. PALLIN, 1979: Apparatus for research on animal ultrasonic signals. Life Sci. Misc. Pub., R. Ont. Mus., Ontario. 